\title{
Poesía y seducción en los escritos estéticos de " $A$ "
}

Luis I. Guerrero

Sacar una frase o un libro entero de su contexto fácilmente conduce a descaminos hermenéuticos; esto puede suceder, con mayores desaciertos, en las obras pseudónimas de Kierkegaard. Su obra entera y especialmente La alternativa forman una red bien definida en sus objetivos ${ }^{1}$. Sus escritos no deben estudiarse de forma fragmentaria, ya que fuera de contexto, pierden su cometido en orden a la verdad existencial que quiere despertar en sus lectores.

No obstante este peligro, existe otro que el propio Kierkegaard preveía: la perversión de sus obras al pretender sintetizarlas y enseñarlas de una manera objetiva. Johannes Climacus apuntó en el Postscriptum, refiriéndose a los pseudónimos:

"Prominentes adjuntos de profesores han desacreditado a los libros pseudónimos, asi como a mi pequeña obra, por no ser didácticos. Muchos han concluido inmediatamente que se debía a que los autores, y yo también, éramos incapaces de elevarnos a las alturas requeridas para instruir didácticamente a la objetividad, que es la posición de los adjuntos de profesores. Quizás es así, pero supongamos que la subjetividad es la verdad; entonces las elevadas alturas de los adjuntos de profesores ciertamente se harían precarias" 2 .

Teniendo en cuenta estos antecedentes, considero que la forma adecuada de transmitir el pensamiento existencial de Kierkegaard

${ }^{1}$ Mi punto de vista. SV2 XIII 559.

2 Postscriptum. Un vistazo a un esfuerzo contemporáneo en la literatura danesa. SV2 VII 266. 
consiste en promover la lectura de sus obras y fomentar el diálogo entre sus lectores. De esta forma quedarán excluidos algunos modos inadecuados de presentación. Quiero ahora referirme a un error concreto: la moralización simplista de sus obras estéticas. No pongo en duda que las obras estéticas persigan un fin que las trascienda, que forman parte de la comunicación indirecta; sin embargo, ese fin, esa forma de comunicación, sólo se consigue - en el contexto kierkegaardiano- dejando obrar a las obras estéticas por si mismas. La presentación estética debe hacerse dentro de categorias estéticas ${ }^{3}$.

Sirva lo dicho hasta este punto para justificar la presentación que haré a continuación, concebida dentro del marco de un simposio kierkegaardiano que reúne a personas que conocen la obra del filósofo danés en su conjunto y aquellas otras que el evento mismo las invita a conocerla. No pretendo sacar una conclusión edificante, ni mostrar los elementos autobiográficos de Kierkegaard. Mi propósito es simple: mostrar por medio de textos, entresacados de la primera parte de La alternativa, algunos rasgos característicos del análisis que hace el 'esteta $\mathrm{A}^{\text {'4 }}$ en el terreno de la poesía y la música.

Por estar dentro de los dominios de la inmediatez estética ${ }^{5}$ y

${ }^{3}$ Cfr. Mi punto de vista. SV2 XIII 567. MackeY, L. Kierkegaard: $A$ Kind of Poet. University of Pennsylvania Press, Philadelphia, 1971. Preface IX-X. No desconozco, por otro lado, la crítica que hace Johannes Climacus al 'esteta A' en el Postscriptum. Cfr. SV2 VII 238.

4 En la versión original Victor Eremita -personaje creado por Kierkegaard- editor de los papeles que contienen La alternativa, da al escritor de la parte estética el nombre de 'A'; sin embargo, para no confundir fonéticamente su nombre, en esta lectura, lo llamaremos el 'esteta $A$ '. Cfr. SV2 I XI-XII.

5 Cfr. Guerrero M., LuIs. Kierkegaard: los limites de la razón en la existencia humana. Publicaciones Cruz, México 1993, p. 180. 
por la amplia gama de temas que desarrolla en sus escritos el 'esteta A', centraré la atención en dos nociones que están continuamente presentes en él: el poeta y la seducción. Ambas nociones estrechamente vinculadas a la pena como categoría estética.

El $\pi \alpha \theta 0 \sigma$, además de la capacidad de despertar y transformar los sentimientos, tiene un elemento, que unido al genio artístico puede ubicar la pena dentro de las categorías estéticas, en esto,

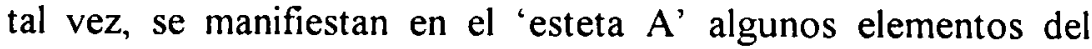
Romanticismo de su siglo. De la misma forma como los griegos elevaron lo trágico a la belleza artística, el 'esteta A' eleva lo patético al ámbito de la poesía; el primer aforismo de "Diapsálmata" es una muestra de ello:

"¿Qué es un poeta? Es un hombre desgraciado que oculta profundas penas en su corazón, pero cuyos labios están hechos de tal suerte que los gemidos y los gritos, al exhalarse, suenan como una hermosa música. Al poeta le acontece como a los pobres infelices que eran quemados a fuego lento en el interior del toro de Falaris, esto es, que sus gritos no llegaban a los oídos del tirano causándole espanto, sino que le sonaban como la más suave música.

Sin embargo, los hombres se arremolinan en torno al poeta y le ruegan: '¡Canta, canta otra vez!' Que es como si le dijeran: ¡Ojalá que nuevos sufrimientos desazonen tu alma! ¡Ojalá que tus labios sigan siendo los de antes! Porque los gritos nos amedrentarian, pero la música es lisonjera'. Y también los críticos entran a formar parte del coro y dicen: 'Muy bien, puesto que asi lo ordenan los cánones de la estética': Claro que un crítico se parece muchisimo a un poeta, con la sola diferencia que no tiene penas en el corazón ni música en los labios.

Por todo esto, antes que ser poeta e incomprendido de los hombres, yo preferiria ser porquerizo junto al puente de Amager. 
y que los cerdos llegaran a comprenderme"6.

¿Cuál es el temperamento del 'esteta A'? ¿Es un crítico del arte y especialmente de la poesia y de la música? ¿Él mismo es un poeta? "Diapsálmata" muestra la personalidad de un hombre que sabe el alcance de ser poeta y parece querer huir de la condena aplicada a los poetas, dedicándose a la crítica estética.

La alternativa nos muestra a un entusiasta y agudo crítico del arte, pero también nos encontramos con papeles que van más allá del estudio; el mejor ejemplo lo tenemos en "El diario de un seductor". La temática de este diario está presente en los diversos estudios críticos del 'esteta A'; asi, en "El erotismo musical" muestra la insuficiencia de algunos intentos de llevar al arte la figura del Don Juan. Solamente Mozart ha conseguido presentar de manera magistral la figura de Don Juan, aunque afirma que puede haber un segundo modo, por medio de la reflexion?. "El diario de un seductor", que no es un estudio crítico sino poesía, constituye esa segunda posibilidad de representar la seducción.

"El diario de un seductor" presenta, sin embargo, dificultades para dar respuesta sobre la personalidad del 'esteta A', ya que no se presenta como su autor, sino solamente como quien edita la narración. Victor Eremita es de la opinión de que se trata simplemente de un viejo truco de novelista y dice del preludio que escribe el propio "esteta A' a "El diario de un seductor": "Lo único que deseo dejar bien anotado es que, en cierto sentido, la atmósfera que domina los preludios del 'esteta $A$ ' nos revela al poeta. Realmente parece como si el propio 'esteta $A$ ' empezara a sentir miedo de su poema, que le inquieta como una pesadilla,

${ }^{6}$ La alternativa. Diapsálmata. SV2 I 3.

${ }^{7}$ Cfr. La alternativa. El erotismo musical. SV2 I 90; Idem, Prólogo. SV2 I XIV. Reflexionen es la palabra danesa usada por el 'esteta A'. 
incluso mientras lo está narrando"8.

El 'esteta A' conoce la enorme diferencia que existe entre un poeta y un crítico, afirma con su aguda ironía: "Claro que un crítico se parece muchísimo a un poeta, con la sola diferencia que no tiene penas en el corazón ni música en los labios"9. Esta diferencia fue señalada por Kant en su Crítica del juicio, afirmando que no corresponde al poeta en su genialidad el hacer critica: "Para el juicio de objetos bellos, como tales, se exige gusto; pero para el arte bello, es decir, para la creación de tales objetos, se exige genio. El genio no puede él mismo descubrir o indicar científicamente cómo realiza sus productos, no sabe cómo se encuentran en él las ideas para ello, ni tiene poder para encontrarlas cuando quiere"10. Así las cosas, si consideramos al 'esteta $A$ ' como un poeta ¿por qué encontramos tantos ensayos críticos en sus papeles? ¿cómo conciliar en él -si la hay- una doble personalidad?

A mi modo de ver, la respuesta va en la línea de lo que mencionaba arriba: el 'esteta $\mathrm{A}$ ' es un poeta con penas en el corazón y con música en los labios, pero que, consciente de si mismo y atemorizado por el destino de los poetas, busca huir por medio de la crítica estética. El 'esteta $A$ ' constituye -ésta es una tesis que sustento con sus propios textos- la personalidad poética (genial, usando el término kantiano) con la mayor relación posible a la reflexión. El destino permanece incólume a ese deseo de huir y produce, en medio de la crítica estética, la música propia del poeta. Los papeles del 'esteta $A$ ', en conjunto, reflejan este estado de cosas, son un poema a la pena que solamente puede hacerse desde la reflexión. Tiene el genio y la sensibilidad necesaria para mostrar a los hombres el papel que la

\footnotetext{
${ }^{8}$ La alternativa. Prólogo. SV2 I XIV.

${ }^{9}$ La alțernativa. Diapsálmata. SV2 I 3.

${ }^{10} \mathrm{KANT}$. Critica del juicio. Primera parte. libro II. $\$ 46 y+8$.
} 
pena puede tener en el arte bello. "No en vano se llama sacerdotes a los poetas, ya que explican la vida. La masa de los hombres, sin embargo, no comprende a los poetas, solamente los comprenden aquellos que tienen corazón sensible" 11 .

El 'esteta $A$ ' dirige una serie de ensayos a los hermanos cosepultos $(\Sigma \psi \mu \pi \alpha \rho \alpha v \varepsilon \kappa \rho \omega \mu \varepsilon v o t)^{12}$. Ésta es una sociedad o cofradia de poetas muertos. El ambiente no puede ser más propicio para explayar el contenido de su corazón. Algunos textos nos pueden ser útiles para introducirnos en este ambiente:

"Hoy celebramos el primer aniversario de la fundación de nuestra cofradia. Este fausto suceso nos brinda de nuevo la oportunidad de reunirnos, precisamente a la hora del crepúsculo vespertino, cuando está para caer el dia más largo de todos y ya empieza a anunciarse la victoria de la noche. El día de nuestra espera ha sido largo, muy largo. Hace apenas un instante que lamentábamos su excesiva duración. Mas ahora nuestra desesperación se ha trocado en alegría. Es cierto que la victoria es pequeña, pues la luz diurna domina aún la faz de la tierra, pero todos sabemos que están contados los minutos de su dominio" 13 .

La pena busca preferentemente el silencio, la soledad, la obscuridad; cuando se le sonrie a la luz o se forma parte del ruido cotidiano tenemos sólo una apariencia, pues la pena evita su manifestación ante el mundo; solamente se puede abrir el corazón ante los hermanos cosepultos, en el mismo lenguaje que los $u^{14} e^{14}$. Este lenguaje es fragmentario y póstumo.

"Caractericemos, pues, nuestra tendencia como un ensayo de

11 La alternativa. Repercusión de la tragedia antigua en la moderna. SV2 I 148 .

12 Cfr. Pap. II 245.

13 La alternativa. Siluetas. SV2 I 167.

14 No es de extrañar que los papeles del 'esteta $A$ ' sean editados'sin su voluntad por Victor Eremita. Cfr. La alternativa. Prólogo. SV2 I XIII. 
esfuerzos fragmentarios o, si se prefiere, como un ensayo en el arte de escribir papeles póstumos. Porque un trabajo completamente terminado no guarda ninguna relación con la personalidad poética. En cambio, cuando se trata de papeles póstumos y en razón de su misma discontinuidad y desconexión, uno siempre siente la necesidad de imaginarse simultáneamente la personalidad del que los ha escrito. Los papeles póstumos son semejantes a unas ruinas, ¿y qué refugio hay más natural que éste para unos sepultados? El arte, pues, consiste en producir artísticamente la misma impresión, el mismo desaliño e interinidad, y el mismo pensamiento anacoluto que son característicos de ese lugar desamparado. El arte está en producir un gozo que en ningún caso sea del momento presente, sino que entrañe siempre algo esencial del tiempo pasado, algo que así sea presente en el tiempo pasado. Esto es lo que expresa la misma palabra: póstumo. En cierto sentido, todo lo que crea un poeta es. póstumo"15.

La pena - a diferencia de la angustia- hace referencia al pasado, y especialmente al recuerdo. La pena no es inquietada por ninguna ilusión futura, pues para ella no existe ya ningún futuro. Los muertos tienen pasado pero no futuro. El 'esteta $A$ ' sabiéndose escuchado por sus cofrades cosepultos puede proponer la más profunda reflexión poética sobre la pena; es muy elocuente la hoja inicial con la que comienza uno de sus discursos:

is La allernativa. Repercusión de la tragedia antigua en la moderna. SV2 I
149-150. 
Copyright of Tópicos. Revista de Filosofía is the property of Universidad Panamericana and its content may not be copied or emailed to multiple sites or posted to a listserv without the copyright holder's express written permission. However, users may print, download, or email articles for individual use. 